\title{
Correction to: Fabrication of gold-silver bimetal nanoparticles/silicon nanoporous pillar array substrate and surface-enhanced Raman scattering detection
}

\author{
Lingling Yan ${ }^{1} \cdot$ Guoxiang Zhang ${ }^{1} \cdot{\text { Hongxin } \mathrm{Cai}^{1}{ }^{1} \cdot \text {. Peng Yang }}^{1} \cdot$ Liang Chen $^{1} \cdot$ Yongqiang Wang $^{1}$ \\ Published online: 15 March 2021 \\ (c) The Author(s), under exclusive licence to Springer-Verlag GmbH, DE part of Springer Nature 2021
}

Correction to: Applied Physics A (2020) 126:957

https://doi.org/10.1007/s00339-020-04141-w

In the original publication of the article, the number of the National Natural Science Foundation of China was incorrect. The correct number is 61705062 .

Publisher's Note Springer Nature remains neutral with regard to jurisdictional claims in published maps and institutional affiliations.

The original article can be found online at https://doi.org/10.1007/ s00339-020-04141-w.

Hongxin Cai

me2001@hpu.edu.cn

1 School of Physics and Electronic Information Engineering, Henan Polytechnic University, Jiaozuo 454000, China 